\title{
A NOTE ON THE ECLECTICISM OF HIPPOCRATES
}

\begin{abstract}
The article examines some suggested influences on Hippocrates in the work of Alcmeon and Diogenes, assesses their importance and concludes that Hippocrates attempted to reconcile what he found useful in their theories with a mainly empirical approach to anatomy and medicine.
\end{abstract}

Pohlenz's assumption ${ }^{1}$ that the Hippocratics were indebted to the air-theology of Diogenes does less than justice both to the empirical spirit of Hippocrates' medicine as a whole and also to the undoubted influence upon that school of the theories of Alcmeon of Croton. Some re-examination of the extent to which the theories of Diogenes and Alcmeon were accepted by the Hippocratics seems to be required.

A crucial passage is $O n$ Winds 3 in which the writer distinguishes

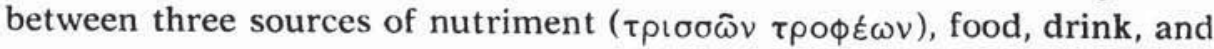

1 Hippokrates tund die Begrïndtung der Wissenschaftlichen Medizin. Berlin 1938 p. $39 \mathrm{et}$ al. Other references to the question are sporadic. Werner Jaeger's Diokles von Karystos, Berlin 1938, p. 216 ff. criticized the facile identification by M. Wellmann (Fragmente der sikelischen Ärzte, Berlin 1901, p. $74 \mathrm{ff}$.) of Empedocles' and Diogenes' accounts of the extent to which the embryo depends upon air as its

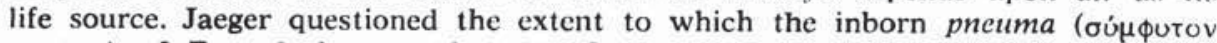
$\pi v \varepsilon \tilde{u} \mu \alpha)$ of Empedocles may be identified with the air-pneumatism of Diogenes. E. Lesky (Die Zeugungs- und Vererbungslehren der Antike, Ak. d. Wiss. u. d. Lit., Mainz 1950) and Solmsen ("The Vital Heat, the Inborn Pneuma and the Aether", JHS 77, 1957, p. 119 ff.) both contented themselves with little more than criticisms of Wellmann's basic assumptions. H. Fränkel (Wege und Formen Frïhgriechischen Denkens, Munich 1955, p. 279 ff.) and R. B. Onians (Origins of European Thought. Cambridge 1954, pp. 36, 47 ff.) made more comprehensive study of the concept of pneuma and the cardiac region in Empedocles, Alcmacon, and Diogenes. Their separate influence upon Hippocrates has, however, been largely ignored until H. A. T. Reiche's more recent study (Empedocles' mixture, Eudoxan astronomy and Aristotle's connate pneuma, Amsterdam 1960, p. $30 \mathrm{ff}$.). Reiche's statement of the problem is brief but clear; he does not, however, place sufficient emphasis upon the empiricist characteristics of the Hippocratics which made possible their eclectic adoption of conflicting elements in the theories of Alcmeon and Diogenes. This is the tentative contribution of the present paper. 


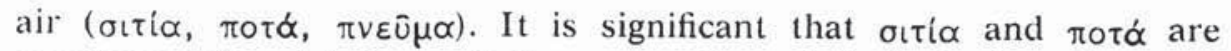
merely mentioned before a fuller explanation of the inclusion of $\pi v \varepsilon \hat{u} \mu \alpha$ is undertaken. It may be that we are witnessing here the conflict between the empirical view of the practising physician who would record the most obvious (to him) sources of nutriment before he proceeds to the necessary elaboration of a less commonly received idea which had originated elsewhere in the school of Diogenes. But the air-theology of the latter reappears in a new guise, in the empirical observations of a physician dedicated to painstaking observation of climatic changes and their effects on the human body. This may be why the implicit acceptance by the Hippocratics of Diogenes' general view that climate intimately affects human beings requires a lengthier (? apologetic) treatment after the rather perfunctory mention of "the air within the body". In this passage the writer expatiates in colourful and rhetorical prose on the powerful and ubiquitous influence of wind going far beyond what his particular medical subject-matter requires ${ }^{2}$.

Again, in the treatise On the Sacred Disease 19, acceptance of Alcmaeon's theory of cephalocentricity is further developed under the obvious influence of Diogenes' theory ${ }^{3}$. The main discussion is then resumed in a more didactic, less colourful prose style which suggests that such sections are probably best regarded almost as "purple passages", where the views and interests of the practising doctor are enhanced by philosophical illustration.

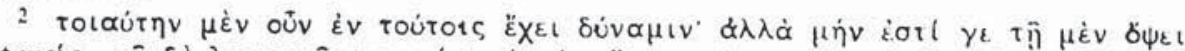

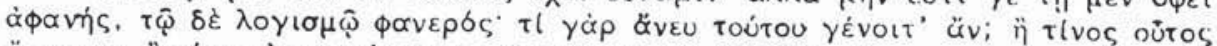

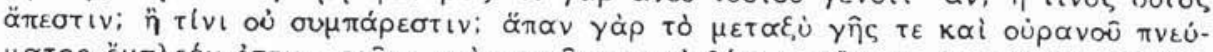

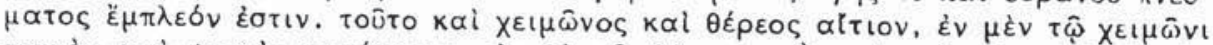

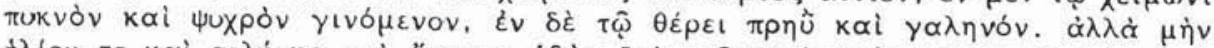

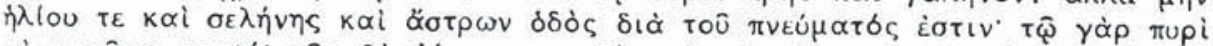

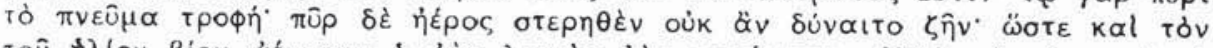

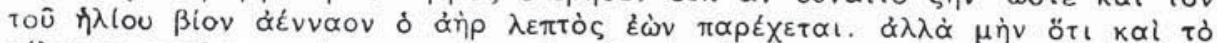

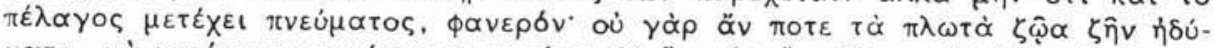

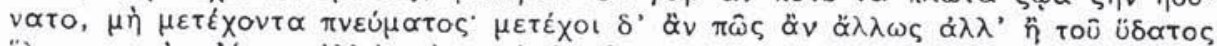

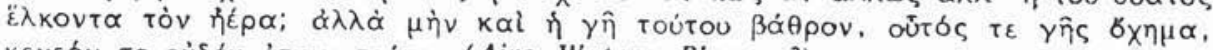

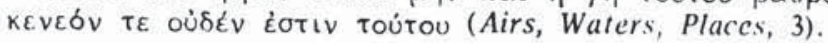

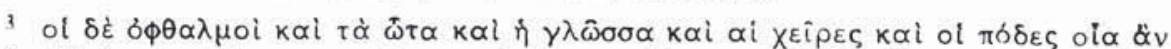

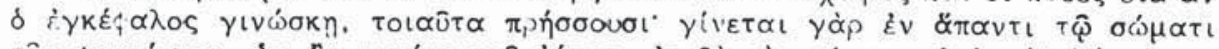

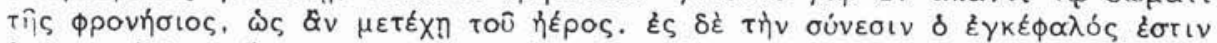

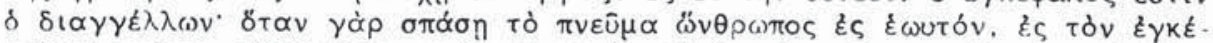

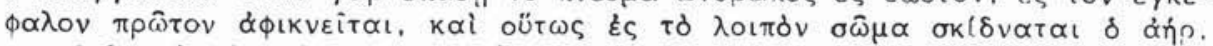

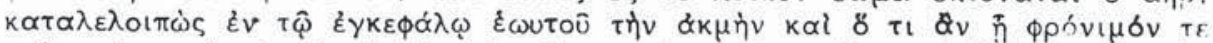

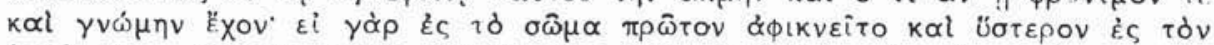

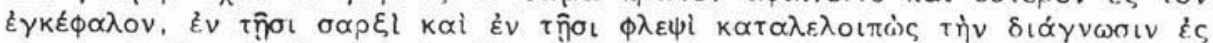

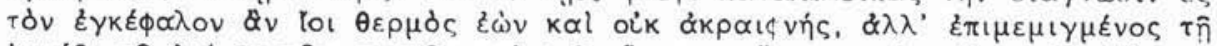

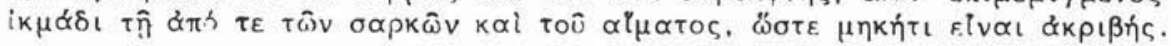


Elsewhere ${ }^{4}$ the accepted link between climate and health is developed at length, and the empirical manifestations of such a link are illustrated, but without any specific reference to Diogenes' air theology.

The incompatibility of Hippocrates' two major sources has caused some commentators ${ }^{5}$ to attribute to Hippocrates a degree of ratiocinative reconciliation of contemporary conflicting influences which is both unnecessary and alien to his empirical and eclectic temper. As Reiche admits: "It is the same empiricism... which explains (the Hippocratics') disinclination to assert their positive theoretical position except in broadest outline" ${ }^{6}$. Hippocrates was clearly concerned with empiricist answers to empirical problems. Diogenes and Alcmaeon were influences to be examined and utilized where helpful, but rejected when their theories proved either incompatible or of no practical application.

The treatise On Ancient Medicine illustrates the position of the Hippocratic School if not Hippocrates himself on such influences:

"Wherefore I have deemed that it has no need of an empty postulate, as do insoluble mysteries, about which any exponent must use a postulate, for example, things in the sky or below the earth. If a man were to learn and declare the state of these, neither to the speaker himself nor to his audience would it be clear whether his statements were true or not. For there is no test the application of which would give certainty.

"But medicine has long had all its means to hand, and has discovered both a principle and a method, through which the discoveries made during a long period are many and excellent, while full discovery will be made, if the inquirer be competent, conduct his researches with knowledge of the discoveries already made, and make them his startingpoint. But anyone who, casting aside and rejecting all these means, attempts to conduct research in any other way or after another fashion, and asserts that he has found out anything, is and has been the victim of deception"?

There is no doubt, however, that Hippocratics' acceptance of Diogenes' views was also limited by the characteristic monism of the latter's cosmology. In the passage cited earlier ${ }^{8}$, the Hippocratic writer refers to air as exerting a most important influence upon the human body; for all that, it is the foremost influence among others which are of

4 Airs, Waters, Places, passim.

5 E. g. Reiche, op. cit., p. $30 \mathrm{ff}$.

Ibid., p. 31.

7 C. $1-2$ (Loeb translation).

8 On Winds, 3. 
the same cosmological status as itself. In the Hippocratic view, air clearly enjoyed no mystical predominance over other substances. The epileptic's sufferings were due to the coagulative effects of pus which restricted the passage of air to the brain. There is no hint that if a man loses his reason it is because he is deprived of normal contact with a divine and universal ón $\rho$. The return of health follows a readjustment of the proper equilibrium and this requires the proper proportion of air no less than of the other substances provided by oitl $\alpha$ and $\pi \circ \tau_{\alpha}$.

The undoubted acceptance by the Hippocratic school both of Alcmaeon's discovery of the brain as the central organ of the nervous system and of his general conception of health as the consequence of a right mixture of elements ${ }^{9}$ emphasizes the eclectic quality of Hippocratic doctrine. While the latter was often loud in its criticism of what it regarded as Alcmeon's limited conception of substance and his consequently restriced view of the nature of disease, it retained a modified form of Alcmaeon's kpôoıs in the general notion of the equilibrium of man and environment even if it decried the dangers of such oversimplification in the detailed explanation of disease ${ }^{10}$.

The key to the attitude of the Hippocratics towards both Diogenes and Alcmeon is to be found, I suggest, not merely in the basic incompatibility of Diogenes' monism and Alcmaeon's conception of $\mu i \xi ı$, as Reiche has suggested. The Hippocratic doctors' awareness of the incompatibility did not overcome a basically empiricist spirit of eclecticism which could retain elements of both theories without a complete adherence to either. This spirit is in accord with the general precepts of the Hippocratic Corpus with regard to the formulation of a diagnosis. Both Diogenes and Alcmeon are implied in the reference of the Hip-

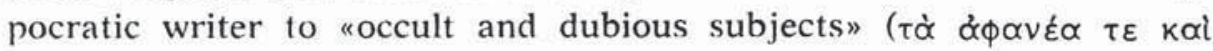

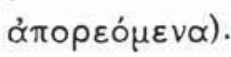

9 On the Sacred Diseasc, 17; Airs, Waters, Places, 12. Cf. Pohlen\%, op. cit., p. 38.

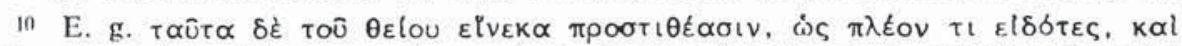

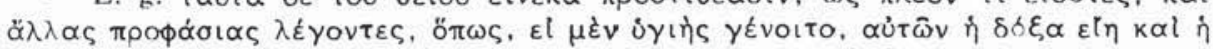

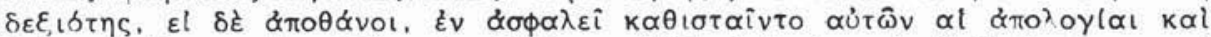

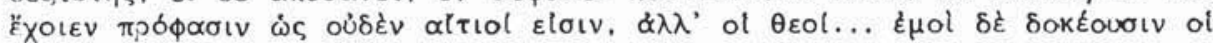

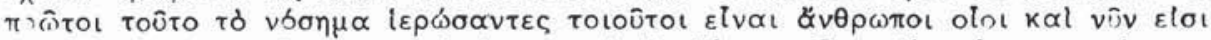

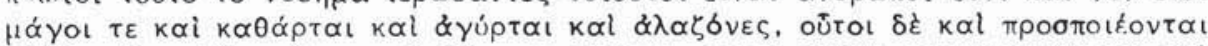

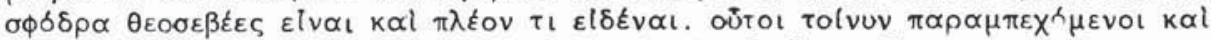

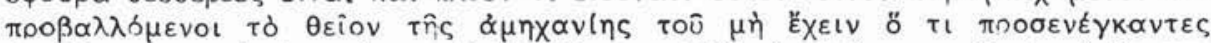

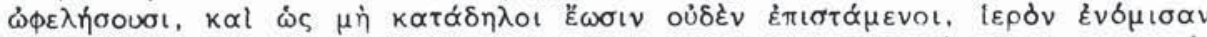

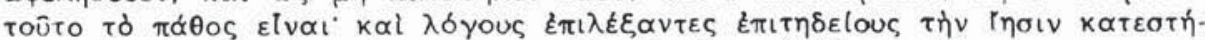

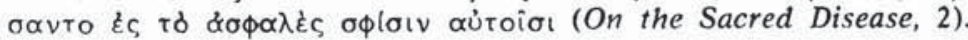


Finally, it may be argued that a distinction must be made between, on the one hand, the theoretical aspects of the theories of Hippocrates himself and, on the other, the more practical outlook of many of his followers who were engaged in day to day medical practice and its attendant problems, and whose views are best exemplified by the writer of On Ancient Medicine". On the other hand we hear of no schism within the School and the writer of the tract is assuming a unity within his own School as he makes his attack on "philosophical medicine». If we accept the consensus view Hippocrates' authorship of the bulk of the Corpus, Hippocrates himself in the rest of his extant writing appears to reflect this spirit of empiricist and eclectic inquiry and practice.

\section{J. C. Davies}

11 Among ancient writers only Erotian ascribes this treatise to Hippocrates himself. Jones (Loeb, vol. I, p. 3 ff.) cites fairly strong internal evidence for regarding Hippocrates as its author but later commentators have been less convinced by his arguments. On balance $O . A . M$. has been generally regarded in ancient and modern times as less likely to have been written by Hippocrates than the other treatises in the Hippocratic Corpus. See, however, the fairly recent article by G. F. R. Lloyd $(C Q, 1975)$ in which previously supposed identical authorship of various sections of the Corpus is doubted. 